\title{
LIFESTYLE PREDICTORS OF OVERWEIGHT AMONG MALAYSIANS
}

\author{
Mary Jane Botabara-Yap ${ }^{1}$, Miriam R. Estrada ${ }^{2}$ and Edwin Balila ${ }^{3}$ \\ ${ }^{1}$ Public Health Department, Adventist University of the Philippines, Putingkahoy, Silang Cavite 4118, Philippines \\ ${ }^{2}$ College of Health, Adventist University of the Philippines, Putingkahoy, Silang Cavite 4118, Philippines \\ ${ }^{3}$ College of Science and Technology, Adventist University of the Philippines, Putingkahoy, Silang Cavite 4118, Philippines
}

Corresponding author: Mary Jane Botabara-Yap

Email: mjbbotabara@aup.edu.ph

\begin{abstract}
The epidemic of overweight is encroaching in the world today, irrespective of economic and social status and regions. It is now seen as a public health threat and one that must be taken seriously in all aspects of public health interventions. There is a need to deeper understand the relationship of lifestyle behaviors and the epidemic of overweight and obesity. This cross-sectional study investigates the lifestyle predictors (smoking, physical activity, diet, and sleeping) of overweight as measured by body mass index (BMI) and waist-to-hip ratio (WHR). A questionnaire survey was conducted among 459 samples (18 years old and above) from those who attended a health screening drive, conducted in three major regions in Peninsular Malaysia. Data were analyzed using descriptive statistics as well as regression model, with $p<0.05$ considered significant. The overall Body Mass Index (BMI) of the population was overweight at 24.69 while the Waist-to-Hip ratio (WHR) for female was 0.86 , classified as high and for male, 0.94 which was borderline. Predictor model revealed that smoking $(P<0.05, R 2$ $0.38)$ and physical activity $(P=0.02, R 2-0.11)$ were predictors for body mass index while smoking $P<0.05, R 2-0.50)$ was a predictor of Waist-to-hip ratio. Findings showed that the problem of overweight in Malaysia is real and smoking and physical activity play a strong role and need to be considered in any public health interventions.
\end{abstract}

Keywords: Overweight, body mass index, waist-to-hip ratio, smoking, physical activity

\section{INTRODUCTION}

The epidemic of overweight is now seen as a public health threat; one that must be taken seriously in all aspects of public health interventions. Not only it has a debilitating impact to the morbidity and mortality of the population but that the economic impact of this rapidly rising phenomenon is affecting both the developed and the developing countries ${ }^{1}$. The World Health Organization (WHO) reports that globally, obesity has almost tripled from 1975 until 2016, where 1.9 billion adults aged 18 years old and above are overweight, of which, 650 million are obese ${ }^{2}$. The problem is not isolated in the developed countries, but is sweeping over the developing countries as well ${ }^{3}$, increasing in all population groups-regardless of gender, sex, race and/or ethnicity, socioeconomic status, education level, and region.

In Malaysia, there was an increase in the overweight and obesity trend from 1996 to 2006; that is, from 4.4 percent to 14.6 percent increase, respectively ${ }^{4}$. Further, it was seen that obesity was greater in women than in men ${ }^{5}$; highest among adults 40-59 years old and highest among Indians, followed by Malays, Chinese, and Aboriginals ${ }^{4}$. To date, Malaysia is now known as the fattest nation in Southeast Asia region ${ }^{6}$.
There are multi-factorial causes of overweight and obesity; some cannot be modified or changed, like age, race, or gender; but lifestyle or behavioral factors such as unhealthy diet, physical activity and/or smoking are modifiable. Lifestyle modifications need to be addressed in conducting individual and population interventions to address the challenges of the growing overweight epidemic ${ }^{7}$. To effectively do this, there is a need to acquire a deeper understanding regarding the relationship of lifestyle behaviors and the growing global and regional epidemic of overweight and obesity. Therefore, this study was conducted to determine the lifestyle predictors of overweight and obesity among Malaysians.

\section{METHODS}

This research utilized 468 respondents based on the data generated from the previous study on the predictors of healthy behaviour among Malaysians8. This research employed descriptive design using questionnaire survey together with biometric testing which was composed of body mass index (BMI), waist-to-hip ratio (WHR), blood pressure and resting heart rate; conducted as part of a countrywide health screening activity targeting individuals who were at risk of chronic diseases. A team of researchers consisting of four trained nurses and a nutritionist conducted the program. 
Free personalized counselling and health education were provided for those participants who were at high risk.

The inclusion criteria for this study include a minimum age of 18 years old, of Malaysian descent, and belonging to three major ethnic groups (Malays, Chinese, and Indians). The study setting was in the three major cities of Peninsular Malaysia (Penang, Kuala Lumpur, and Johor Bahru). It was made to best target urban young adults given the early, preventive focus of this programme. Respondents who attended the free screening programme were inducted into the study if they gave their consent.

The questionnaire underwent a backward-forward translation process by linguistic and technical experts. Preliminary testing through a pilot study was conducted prior to the actual conduction of the data gathering, revealed an alpha of $0.811(n=70)$. For the analysis, this study adopted the Statistical Package for the Social Sciences (SPSS) software version 19.0. Frequencies and percentages were used to compute demographic data, means and standard deviation were used to describe the independent and dependent variables. Further, enter method was employed to determine existing relationships between the independent and dependent variables.

\section{RESULTS}

Overall response rate of this study was good at $98 \%$ $(\mathrm{N}=468)$. Incomplete questionnaires were excluded from the analysis. Table 1 showed the background characteristics of the sample in terms of gender, age and ethnicity. There were more females $(60.8 \%$ or 279$)$ than males $(39.2 \%$ or 180$) ; 276$ or $60.1 \%$ comprise of those aged between 18 to 39,159 or $34.6 \%$ were those $40-59$ years of age while 87 or $19 \%$ belong to 60 years old and above. The overall BMI of the population in this study was 24.69 while the
WHR for female was 0.86 , classified as high and for male, 0.94 with a classification of borderline.

Table 1: Frequency Distribution of Respondents in terms of Gender, Age, and Ethnicity $(n=459)$

\begin{tabular}{lll}
\hline Variables & Frequency & $\begin{array}{l}\text { Percent } \\
(\%)\end{array}$ \\
\hline $\begin{array}{l}\text { Gender } \\
\text { Female }\end{array}$ & 279 & 60.8 \\
$\quad$ Male & 180 & 39.2 \\
Age & & \\
$18-39$ & 276 & 60.1 \\
$40-59$ & 159 & 34.6 \\
$\quad 60$ and above & 24 & 5.2 \\
Ethnicity & & \\
$\quad$ Chinese & 236 & 51.4 \\
$\quad$ Malay & 128 & 27.9 \\
Indian & 87 & 19.0 \\
& & \\
\hline
\end{tabular}

In determining the predictors of $\mathrm{BMI}$ and WHR, the study utilized enter method. Table 2 showed the variables that entered the regression which are considered statistically significant. The highest predictor of BMl was smoking with an unstandardized coefficient of 1.26 , a t-value of 4.09 with a significant value $P<0.05$. This means that the more the respondents smoke, the higher their BMI becomes. Physical activity also entered into regression with unstandardized coefficient of 0.73 , a $\mathrm{t}$-value of 2.29 , and significant value of 0.023 which is also significant at 0.01 level.

The best predictor of WHR was smoking with unstandardized value of 0.03 , a t-value of 4.38 and a significance of $<0.05$. This shows that as the respondents' smoking is increased, the more likely they will have higher WHR. Physical activity did not show significance at 0.062 , a $\mathrm{t}$-value of 1.87 and unstandardized value of 0.01 .

Table 2: Lifestyle Predictors of Body Mass Index (BMI) and Waist-to-hip ratio (WHR) ( $=459)$

\begin{tabular}{|c|c|c|c|c|c|c|}
\hline & $\begin{array}{l}\text { Unstandardized } \\
\text { Coefficients B }\end{array}$ & I. Error & $\begin{array}{l}\text { Standardized } \\
\text { Coefficients B }\end{array}$ & $\mathrm{t}$ & Sig. & $\begin{array}{c}\text { R-Square } \\
\text { Change }\end{array}$ \\
\hline *(Constant) & 20.08 & 1.04 & & & & \\
\hline Smoking & 1.26 & 0.31 & 0.19 & 19.40 & $<0.05$ & 0.49 \\
\hline $\begin{array}{l}\text { Physical } \\
\text { Activity }\end{array}$ & 0.73 & 0.32 & 0.10 & $\begin{array}{l}4.09 \\
2.29\end{array}$ & 0.023 & 0.38 \\
\hline ** (Constant) & 0.79 & 0.02 & & & $<0.05$ & \\
\hline Smoking & 0.03 & 0.01 & 0.20 & $\begin{array}{c}35.58 \\
438\end{array}$ & $<0.05$ & 0.11 \\
\hline $\begin{array}{l}\text { Physical } \\
\text { Activity }\end{array}$ & 0.01 & 0.01 & 0.86 & $\begin{array}{l}4.38 \\
1.87\end{array}$ & 0.062 & 0.50 \\
\hline
\end{tabular}




\section{DISCUSSION}

Many studies showed that not only is WHR closely associated with overweight and obesity but it is also highly associated with other unfavorable conditions such as cardiovascular and stroke problems $\mathrm{s}^{9,10,11}$. It was shown that even women with normal weight, or

The overall BMI of the population in this study exceeds that of the Asian 'normal standard' of 18.522.9 and is categorized as overweight ${ }^{14}$; BMI offers a good indicator of body fatness and is normally used to screen overweight and obesity, especially in a community setting ${ }^{15}$. It is a number obtained from calculating a person's weight in kilogram divided by height in meter squared. The WHO notes that BMI is a simple health index that is used to classify underweight, overweight and obesity among adults, independent of age and gender ${ }^{14}$.

Aside from BMI, this study also utilized the use of WHR ratio to determine the central obesity of the participants. WHR is the result of measuring the narrowest point of the torso (waist) divided by the hip circumference measurement or the widest part of the hip ${ }^{16}$. For both men and women, a WHR of 1.0 or higher is considered "at risk" for undesirable health outcomes (i.e., heart disease) and ailments associated with overweight. A healthy result is 0.90 or less for men, and 0.80 or less for women ${ }^{17}$.

Literature is divided as to the effect of smoking BMI; some say that current smokers have lower BMI and some say, they have higher or it depends ${ }^{18,19,20}$; while current smokers tend to have normal BMI, however, it cannot be said about long-term smokers, who appeared to have higher $\mathrm{BMI}^{21}$. Decrease or increase of BMI may depend on the length of the smoking status of the individual ${ }^{22}$. Authors concluded that the effect of nicotine among short term smokers result in increased energy expenditure thus, reducing appetite, which may explain why smokers tend to have lower body weight than nonsmokers do; moreover, although current smokers have a tendency to be less likely to be obese as compared those who never smoked, however the inverse relationship is not a causal association ${ }^{23}$. In Malaysia, one in five adults smoke or 22.85 prevalence of smokers; the sixth highest in Southeast Asia region ${ }^{24}$.

Physical activity was another predictor of BMI. Surprising result of this study showed that that the higher the engagement in physical activity is, the higher the BMI. Malaysians are generally the least active population group, with almost half of Malaysians are either not exercising at all, or not exercising enough ${ }^{25}$. Generally, we assume that as people engage in physical activity, they eventually lower their body fat; while this may be true to a BMI of less than 25, were of increased risk of developing chronic conditions, if they were carrying that weight around their abdominal area ${ }^{12}$. In Malaysia, females and non-Malays have high abdominal obesity despite the fact that they have normal BMI ${ }^{13}$.

some, however it cannot be generalized. For example, in a cross-sectional analysis of 2,840 participants regarding the relationship of physical activity and BMI, authors concluded that moderate physical activity and lowered BMI were only present among obese participants and not from those overweight or of normal weight ${ }^{26}$. Result was consistent with another study among 151,656 respondents in China over a period of 14 years; result showed that as physical activity increased, there was also a notable increase in overweight and obesity as measured by BMI thus, physical activity alone is not a predictor of normal $\mathrm{BMI}^{27}$, but prolonged sedentary life has an ill effect on health, despite physical activity, including increasing $\mathrm{BMI}^{28}$. Moreover, overweight and obese people, who, despite engaging in physical activity but do not follow the required recommendation of physical activity, did not show changes in BMI ${ }^{29}$.

The only variable that entered into regression and is the best predictor of WHR was smoking; this was confirmed by many studies. For example, in a metaanalysis of 116,146 participants, researchers found a significant link between cigarette smoking and high WHR ${ }^{30}$; also, a Finnish study on the associations between smoking, BMI and waist circumference, result showed that people who used to smoke as well as current smokers tend to have higher WHR and bigger waist as compared to those who never smoked $^{31}$. A meta-analysis study to determine whether smoking is associated with obesity revealed that indeed, increased smoking leads to increased WHR $^{32}$. Currently, there are more than 20\% adult smokers in Malaysia, with the highest prevalence among males and of Malay ethnicicty ${ }^{33}$.

One of the limitations of this study was the use of convenience sampling during the selection of the sample, which as a result, potential bias may occur; however, the population of interest was chosen from the three major cities of the country, with good representation from the three major ethnic backgrounds. Another limitation was the language barrier as some of the respondents were not able to speak English or Bahasa well. However, there were available interpreters during the data collection process in order to assist those who have difficulty in answering the survey questionnaire. 


\section{CONCLUSION}

The findings of this study clearly showed that the main predictors of overweight and obesity among Malaysians are smoking and the lack of sustained physical activity. As the increasing prevalence of overweight and obesity in Malaysia heightens the susceptibility of the population's risk for chronic diseases, result of this study signifies an increasing need of health promotion programs on smoking and physical inactivity. Interventions and strategies aimed at controlling overweight and obesity must incorporate programs on anti-smoking and promotion of physical activity.

\section{ACKNOWLEDGEMENT}

The researchers would like to extend their deepest gratitude to the Malaysian population who participated in this study; also, to the Seventh Day Adventist group of organization in Peninsular Malaysia who assisted the researchers during the data collection, providing the human resource and financial assistance, deep gratitude is extended. Thank you.

\section{REFERENCES}

1. Helble $M$, Francisco $K$. The Imminent Obesity Crisis in Asia and the Pacific: First Cost Estimates. ADBI Working Paper Series; 743; Asian Development Bank Institute; 2017;

https://www.adb.org/sites/default/files/ publication/320411/adbi-wp743.pdf.

2. World Health Organization. Factsheet; Geneva, Switzerland. 2017; https://www.who.int/news-room/factsheets.

3. Bhurosy T, Jeewon R. Overweight and Obesity Epidemic in Developing Countries: A Problem with Diet, Physical Activity, or Socioeconomic Status? Scientific World Journal 2014; 2014:964236.

4. Khambalia AZ, Seen LS. Trends in overweight and obese adults in Malaysia (1996-2009): a systematic review; Obes Rev 2010;11(6):403-12.

5. Chan YY, Lim KK, Lim KH, et. al. Physical activity and overweight/obesity among Malaysian adults: findings from the 2015 National Health and morbidity survey (NHMS); BMC Public Health 2017; 17(1):733.

6. Schoepp T. Obesity in Malaysia: Unhealthy Eating is as Harmful as Smoking. Penang
Institute, Malaysia. 2017 Dec; https://penanginstitute.org/publications/i ssues/1029-obesity-in-malaysia-unhealthyeating-is-as-harmful-as-smoking/.

7. Hruby A, Hu F. The Epidemiology of Obesity: A Big Picture. Pharmacoeconomics 2015; 33(7): 673-689.

8. Botabara-Yap M, Razon-Estrada M, Balila E. The influence of culture and access to healthcare delivery as predictors of health behaviours among Malaysians of different cultural backgrounds. International Forum Journal 2017; 20(2): 57-74.

9. Ashwell M, Gibson S. Waist-to-height ratio as an indicator of 'early health risk': simpler and more predictive than using a 'matrix' based on BMI and waist circumference. BMJ Open 2016; 6:e010159.

10. American Heart Association. Higher waist and hip measures may add up to greater risk for heart attack among women. ScienceDaily.2018 Feb. https://www.sciencedaily.com/releases/2 018/02/180228085425.htm.

11. Fauziana R, Jeyagurunathan A, Abdin E, et. al. Body mass index, waist-hip ratio and risk of chronic medical condition in the elderly population: results from the Well-being of the Singapore Elderly (WiSE) Study. BMC Geriatr 2016; 16:125.

12. Harvard School of Public Health. Measuring obesity: from calipers to CAT scans, ten ways to tell whether a body is fat or lean. USA. 2018; https://www.hsph.harvard.edu/obesityprevention-soource/obesitydefinition/how-to-measure-body-fatness/.

13. Institute for Public Health; National Health and Morbidity Survey 2015 (NHMS 2015). Vol. II: Non-Communicable Diseases, Risk Factors \& Other Health Problems. Kuala Lumpur: Ministry of Health Malaysia 2015; http://iku.moh.gov.my/images/IKU/Docu ment/REPORT/nhmsreport2015vol2.pdf.

14. World Health Organization. BMI classification. Geneva, Switzerland. 2019; https://www. who.int/news-room/factsheets/detail/obesity-and-overweight.

15. Harvard School of Public Health. Measuring body fat; United States. 2019; https://www.hsph.harvard.edu/nutritions 
ource/healthy-weight/measuring-fat/.

16. Centre for Chronic Disease \& Prevention. Body mass index: considerations for Practitioners. United States. 2011; 60(40);1377-1381;

https://www.cdc.gov/obesity/downloads/ bmiforpactitioners.pdf.

17. Norafidah AR, Azmawati MN, Norfazilah A. Factors influencing abdominal obesity by waist circumference among normal BMI population. Malaysian Journal of Public Health Medicine 2013; 13(1): 37-47.

18. Dare S, McKay D, Pell J. Relationship between smoking and obesity: a crosssectional study of 499,504 middle-aged adults in the UK general population. PLOS One 2015; 10(4):e0123579.

19. Gasperin LOF, Neuberger M, Tichy A, Moshammer H. Cross-sectional association between cigarette smoking and abdominal obesity among Austrian bank employees. BMJ Open 2014; 4(7):e004899.

20. Piirtola $M$, Jelenkovic A, Latvala A, et al. Association of current and former smoking with body mass index: A study of smoking discordant twin pairs from 21 twin cohorts. PLoS One 2018; 13(7):e0200140.

21. McKay D, Gray L, Pell J. Impact of smoking and smoking cessation on overweight and obesity: Scotland-wide, cross-sectional study on 40,036 participants. BMC Public Health 2013; 13(348).

22. Mathew A, Kurian R, Akshay KM, et. al. Association between smoking and body mass index among males aged 20 years and above: A study in rural Tamil Nadu, South India. South East Asia Journal of Public Health 2015; 4(1): 53-58.

23. Rezaei S, Hajizadeh M, Pasdar $\mathrm{Y}$, et. al. Association of smoking with general and abdominal obesity: evidence from a cohort study in west of Iran; Journal of Research in Health Sciences 2018; 18(1): e00401.

24. The Star Malaysia. $80 \%$ of smokers live in poorer countries; Malaysia. 23 May 2017. https://www.thestar.com.my/opinion/lett ers/2017/05/23/80-of-smokers-live-in- poorer-countries/.

25. Tam CL, Bonn G, Yeoh SH, Yap CC, Wong $\mathrm{CP}$. Physical activity and its correlates among adults in Malaysia: a cross-sectional descriptive study. PLOS One 2016; 11(6):e0157730.

26. Dickerson J, Smith M, Benden M, Ory M. The association of physical activity, sedentary behaviors, and body mass index classification in a cross-sectional analysis; BMC Public Health 2011; 11:926.

27. Tian $\mathrm{Y}$, Jiang $\mathrm{C}$, Wang $\mathrm{M}$, et. al. BMI, leisuretime physical activity and physical fitness in adults in China: results from a series of national surveys; Lancet Diabetes Endocrinol 2016; 4(6), 487-497.

28. Biswas $A$, Oh $P$, Faulkner $G$, et. al. Sedentary time and its association with risk for disease incidence, mortality, and hospitalization in adults: a systematic review and meta-analysis; Ann Intern Med 2015;162(2):123-132.

29. Moholdt T, Lavie C, Nauman J. Interaction of physical activity and body mass index on mortality in coronary heart disease: data from the Nord-Trøndelag Health Study. Am J Med 2017;130(8);949-957.

30. Lu S, Ruopeng A, Van Meijgaard J. Cigarette smoking and abdominal obesity: a metaanalysis of observational studies. Journal of Substance Use 2013; 18(6); 440-449.

31. Tuovinen EL, Saarni SE, Maanisto S, et. al. Smoking status and abdominal obesity among normal and overweight/obese adults: Population-based FINRISK study. Prev Med Rep 2016;4:324-330.

32. Morris RW, Taylor AE, Fluharty ME, et. al. Heavier smoking may lead to a relative increase in waist circumference: evidence for a causal relationship from a Mendelian randomization meta-analysis. The CARTA consortium. BMJ Open 2015; 5:e008808.

33. Lim $\mathrm{KH}$, Teh $\mathrm{CH}$, Pan S, et. al. Prevalence and factor/s associated with smoking among adults in Malaysia - findings from the National Health and Morbidity Survey (NHMS) 2015. Tob Induc Dis 2018;16:1. 